\title{
Competencia de arbitraje en Washington D. C.: ¿una simple competencia o una experiencia indispensable para el futuro ejercicio profesional?
}

\section{Rodrigo Molina Cabrera ${ }^{1}$}

En primer lugar, quisiera agradecer a la revista oficial de la Facultad de Derecho de la Universidad de Lima, Ius et Praxis, por la invitación para escribir en la presente edición.

\section{Introducción}

Esta reseña la escribo para incentivar a los alumnos de nuestra Facultad de Derecho a participar en contiendas jurídicas en las que puedan practicando para lo que viene en el futuro - aplicar los conocimientos adquiridos en las aulas para, como abogados defensores, velar por los intereses de un hipotético cliente, enfrentándose a otro grupo de estudiantes, nacionales o de otros países, que tienen la misma misión: convencer a un tribunal o jurado de la solidez de su posición y obtener un fallo favorable a su cliente.

En otras palabras, a los estudiantes se nos brinda la posibilidad de hacer una simulación de lo que vamos a hacer en el futuro, que es convencer de nuestra posición a un juez, árbitro o funcionario público, de tal manera que podamos salvaguardar los intereses de nuestros potenciales clientes.

1 Bachiller en derecho por la Universidad de Lima en el 2012. Asociado del Estudio Rodrigo, Elías \& Medrano Abogados. 
Algo importante, que no se debe perder de vista, es que no solo los abogados "procesalistas" son los que litigan: también el tributarista debe convencer (y hace informes orales, por cierto) a la Sunat y al Tribunal Fiscal de que su cliente, por ejemplo, dedujo correctamente ciertos gastos; e igual, quien trabaja temas de derecho financiero deberá presentarse ante la Superintendencia del Mercado de Valores para demostrar, por ejemplo, que su empresa no incumplió la Ley del Mercado de Valores y no debe ser sancionada por una emisión de bonos hecha conforme a ley. Y así pasa con todas las ramas del derecho.

Pues bien, la capacidad de convencer a un juez, árbitro o funcionario público no es algo que se aprenda en las aulas. En ellas, sí, aprenderemos todas las herramientas legales para que, utilizando habilidades argumentativas, consigamos un resultado favorable para nuestros clientes.

Y esas habilidades argumentativas, ¿cómo se desarrollan? La respuesta es sencilla: con la participación en competencias académicas en las que se pueda desarrollar no solo la capacidad de convencer a un tercero, sino de refutar rápidamente la posición de una eventual contraparte.

Con esa idea, por iniciativa de importantes universidades de Sudamérica y con la organización de la Universidad Nacional de Buenos Aires (UBA) y la Universidad del Rosario de Bogotá, se llevó a cabo, en el 2007, la primera edición de una competencia en la que alumnos de distintas universidades de esta parte del continente actúan como abogados de las partes en un caso simulado, defendiendo los intereses de sus hipotéticos clientes (primero en forma escrita y luego en forma oral) ante tribunales arbitrales integrados por prestigiosos árbitros internacionales, abogados y académicos, que tienen a su cargo la tarea de evaluar y calificar las presentaciones escritas y orales de los equipos.

Esa competencia, qué duda cabe, y como bien se señala en un portal web, ${ }^{2}$ es una idea "educativa con formato competitivo, cuyo propósito es fomentar el estudio del derecho comercial internacional y el arbitraje como método de resolución de conflictos".

$Y$ aunque nuestra universidad participó en esa competencia por primera vez, en el 2011, en Buenos Aires, durante su cuarta edición, en las líneas que siguen describiré y relataré todo lo relativo a la quinta edi-

$2<$ http://www.wcl.american.edu/arbitration/competencia.cfm>. 
ción de la Competencia Internacional de Arbitraje (en adelante, la Competencia), realizada en el 2012, en la que me tocó ser parte del grupo de alumnos que representó a la Facultad de Derecho de la Universidad de Lima.

Nuestro equipo estuvo conformado por Gabriel Boucher, Francisco Carrillo, Mariana González-Prada, Joyce Moore Murphy y quien esto escribe.

¿Alguna particularidad distinguió a la Competencia de dicho año? Pues sí, hubo una novedad: a las universidades antes mencionadas se incorporó, como coorganizadora, la American University Washington College of Law, que sería sede de la Competencia.

\section{El formato de la Competencia}

La Competencia gira en torno al debate frente a un caso hipotético que, visto desde la parte del demandante y del demandado, deberá ser defendido por cada grupo universitario.

Desde febrero del 2012, constaba en el portal web de la Competencia el caso consistente en un supuesto incumplimiento contractual de una empresa pública, a la que se llamó Hydrofuerza S. A. (en lo sucesivo, Hydrofuerza), en el marco de un contrato de joint venture celebrado con una empresa privada extranjera, que se denominó Boulder Dam S. A. (en adelante, Boulder), para la construcción y operación de una central hidroeléctrica en un país inventado: "Costa Dorada".

¿Suena conocido? Claro que sí. En nuestro país, la mayoría de las concesiones para la construcción y operación de este tipo de centrales se otorgan -luego del procedimiento de licitación correspondiente- a empresas extranjeras.

Más conocida debe sonar una controversia que surgió en la ejecución contractual del caso planteado: algunos manifestantes realizaron bloqueos en la zona donde se venía construyendo la central hidroeléctrica, aduciendo supuestas "infracciones ambientales" que, cosa curiosa $-\mathrm{y}$ recordamos casos en nuestro país -, nunca fueron probadas.

De esa situación surgen varias circunstancias que complican la ejecución contractual. Por ejemplo, la construcción de la central hidroeléctrica se paraliza y, como el contrato así lo preveía en ciertos supuestos, Hydrofuerza contrata a un tercero para que "culmine" aquello iniciado por la empresa privada. 
Por otro lado, y volviendo al formato de la Competencia, es pertinente indicar que las reglas de procedimiento y normas aplicables eran la Ley Modelo de Arbitraje Comercial de CNUDMI/Uncitral, así como los Principios Unidroit sobre Contratos Comerciales Internacionales.

Pues bien, una vez inscritos y considerando las reglas, debíamos presentar en junio del 2012 la "memoria del demandante"; dicho en términos más conocidos: enviar por correo electrónico nuestra demanda arbitral.

La demanda debía ser preparada por nuestro grupo tomando en cuenta los datos del caso publicados; como es obvio, el planteamiento, los argumentos y la estrategia dependían de lo que nuestro grupo considerara pertinente. Así, debíamos preparar, cuales abogados, la estrategia para ganar la controversia suscitada.

Según como se planteaba el caso, era Boulder (la empresa privada) quien debía ser la demandante, y eso lo tuvimos en cuenta. Siendo así, luego de esperar algunos meses nos llegaría - vía correo electrónicouna demanda elaborada por algún grupo universitario nacional o internacional, a la que debíamos contestar por el mismo medio.

Y eso hicimos. Contestamos la demanda tomando como "patrocinada" a la empresa estatal.

Nótese, entonces, que los grupos debían colocarse en ambas posiciones. Lo recomendable, dada dicha situación, era separar al grupo en "subequipos" que se encargaran de cada posición. Ello servía además para practicar la fase oral, que venía dentro de poco.

Luego nos tocó prepararnos para la fase oral, que se daría en setiembre del 2012. De hecho, con los cursos en la universidad y las prácticas preprofesionales, era difícil contar con tiempo para poder emplearlo en la práctica de la parte oral de la Competencia, pero nos hicimos del tiempo necesario practicando en diversas oportunidades durante la semana.

Nos llamó la atención que, algunos meses antes de la fase oral, nos enviaran por correo electrónico las "memorias" de los grupos universitarios contra quienes nos enfrentaríamos en las audiencias arbitrales, tal cual un proceso arbitral. Claro, no podíamos presentar un escrito refutando sus argumentos, pero sí podíamos elaborar nuestras presentaciones "conociendo" sus fundamentos, con vistas al momento en que nos enfrentaríamos. 
Llegó setiembre. A fines de dicho mes debíamos viajar a Washington D. C., para participar en las audiencias enfrentándonos a grupos universitarios de diversos países.

En las audiencias, el formato era muy simple. Cada parte, en principio, contaba con treinta minutos para una presentación inicial del caso ante el tribunal arbitral. Primero lo haría la empresa demandante; luego le tocaría el turno a la empresa demandada. Posteriormente, según lo acordado entre las partes, se concedería un plazo para la réplica y dúplica respectiva, en donde se refutarían los argumentos planteados por cada parte.

Por último, si el tribunal lo consideraba conveniente, podía hacer preguntas a las partes en litigio; de hecho, algunos árbitros preguntaron durante la exposición, sin esperar a que terminara.

Se imaginan el nerviosismo de estar hablando por primera vez frente a un tribunal y, de pronto, uno de los árbitros te "corta" la exposición para hacerte una pregunta. La verdad que era complicado, pero formaba parte de lo difícil que era desenvolverse en las audiencias.

En la primera ronda fueron cuatro las presentaciones de cada equipo. El tribunal contaba con nueve puntos para otorgar; dicho de otro modo, cada árbitro (eran tres) podía otorgar tres puntos a cada equipo. Por ejemplo, si durante una audiencia el árbitro " $\mathrm{A}$ " le otorgaba tres puntos al equipo " $\mathrm{x}$ " $\mathrm{y}$ ninguno al equipo " $\mathrm{y}$ ", $\mathrm{y}$ los árbitros " $\mathrm{B}$ " $\mathrm{y}$ " $\mathrm{C}$ " le otorgaban, cada uno, dos puntos al equipo " $\mathrm{x}$ " $\mathrm{y}$ un punto al equipo " $y$ ", entonces el equipo " $x$ " ganaba dicha audiencia con siete puntos, frente a los dos puntos del equipo " $y$ ".

Los grupos que obtuvieran los mayores puntajes pasarían a la segunda ronda, en la que se utilizaría el mismo formato, con la diferencia de que la eliminación sería directa. Luego comenzarían los "octavos de final", hasta llegar a la final.

Realizada la final, en una ceremonia especial se entregarían diversos premios:

a. Mejor memoria del demandante

b. Mejor memoria del demandando

c. Menciones honrosas a diversos oradores

d. Mejor orador

e. Ganador del certamen 


\section{El caso que nos tocó enfrentar en la Competencia y nuestra posición sobre cada tema relevante}

Como adelantamos, se trata de la controversia surgida en la ejecución de un contrato de joint venture celebrado entre una empresa estatal de Costa Dorada y la empresa privada Boulder.

En vista de la falta de electricidad en Costa Dorada y dado que la empresa estatal (Hydrofuerza) no contaba con el know how necesario para construir una central de electricidad de grandes magnitudes, se convocó a una licitación pública que concluyó con la elección de Boulder como la empresa que la construiría.

Con la autorización respectiva del Ministerio de Obras Públicas, Transporte e Infraestructura de Costa Dorada y con su financiamiento para el pago de la contraprestación a Boulder, se suscribió el contrato de joint venture para la construcción y operación de la Central Heráclito.

En el contrato se dividió la ejecución del proyecto en diversos "hitos" o etapas en las que debía Boulder - necesariamente- llegar a un porcentaje determinado de la obra para que se le pagara la correspondiente cuota.

Algo llamativo es que en el contrato no se indicó cuál sería la moneda de pago, sino que solo se mencionó que se pagaría un "equivalente" a cierta cantidad dólares. Esto llevó a que se pagara, primero, en dólares $\mathrm{y}$, luego, en moneda nacional, en la cantidad equivalente. ¿Era correcto este cambio? Es discutible.

Tampoco se estableció el lugar de pago, lo que provocó otra situación de dificultad en la interpretación y ejecución del contrato.

Reiteramos: ambas circunstancias traerían problemas en la ejecución contractual.

Otro problema - en realidad, el más importante del caso- es que, en plena ejecución del contrato, varios manifestantes de la zona de Heráclito (donde se construía el proyecto) tomaron la carretera, lo que hizo imposible que los trabajadores de Boulder pudieran continuar con la construcción de la central hidroeléctrica.

¿Cuál es el problema con ello? Que dicha circunstancia "imprevisible" evitó que se cumpliera con el avance de las obras requerido para cierta fecha, por lo que Hydrofuerza no pagó la contraprestación, argumentando que, a pesar de la circunstancia referida, Boulder tenía la obligación de avanzar conforme a lo pactado en el contrato. 
Es más, utilizando una facultad prevista en el contrato, Hydrofuerza decidió la contratación de un tercero para que, en nombre y a costo de Boulder, concluyera la construcción de la central.

Por último, en vista de que Boulder no cumplió con el pago al tercero (Fast Solutions S. A.) que concluyó la obra, Hydrofuerza, por incumplimiento "insubsanable" (término definido en el contrato), resolvió el vínculo contractual con la primera.

De ello, como puede apreciarse, surgen varios temas controvertidos. A continuación desarrollamos estos y otros temas de controversia que fueron discutidos en la Competencia, precisando que hacemos el análisis, no desde la perspectiva del demandante o del demandado, sino desde cuál -a mi criterio- era la posición jurídicamente correcta.

\section{a. El Estado es parte no signataria del contrato}

Un primer tema que se debe dilucidar es si el Estado de Costa Dorada (en adelante, el Estado) debió o no ser incluido como demandado en el arbitraje, en tanto no fue parte del contrato suscrito.

Pensamos que el Estado puede ser demandado, considerándolo como parte no signataria del convenio arbitral, pues sin su participación, la materialización del contrato no hubiera sido viable por las siguientes razones:

- El Estado financia el pago de la obra en su totalidad.

- El Estado autoriza la celebración del contrato y la resolución de este.

- La cláusula once del contrato señala: “[...] el representante del MOPTI podrá requerir formalmente en cualquier momento el cumplimiento de las obras en caso de que no se estuviesen cumpliendo los hitos establecidos en el cronograma".

- Por lo demás, su participación en el contrato y sus potestades no se limitan a las mencionadas, sino que, en virtud de la misma cláusula el Estado, podía incluso “[...] revisar los aspectos económicos financieros del contrato".

Para hacer un símil con la regulación, en el Perú, de las partes no signatarias, podríamos decir que estamos en el supuesto del artículo 14 del Decreto Legislativo 1071: 
El convenio arbitral se extiende a aquellos cuyo consentimiento de someterse a arbitraje, según la buena fe, se determina por su participación activa y de manera determinante en la negociación, celebración, ejecución o terminación del contrato que comprende el convenio arbitral o al que el convenio esté relacionado. Se extiende también a quienes pretendan derivar derechos o beneficios del contrato, según sus términos (resaltado nuestro).

Como se ha indicado, la participación del Estado es tanto activa como determinante; ergo, su condición como parte no signataria es ciertamente evidente.

\section{b. Sobre la responsabilidad "solidaria" del Estado}

El segundo aspecto que se discutió en la Competencia fue verificar si el Estado debe responder de manera solidaria por los incumplimientos imputados por Boulder a Hydrofuerza.

Partiendo de la premisa de que el Estado era el único accionista de esta última, puede señalarse que ejercía su control total. Sostener lo contrario sería forzado, pues Hydrofuerza es una empresa que: a) solo realiza actividades en beneficio del Estado (suministro de energía eléctrica y construcción de centrales); y b) tiene un patrimonio prácticamente nulo; su único sustento es lo que tiene su accionista: el Estado.

Pero ¿cómo hacer que un accionista responda solidariamente por obligaciones a cargo de la sociedad?

Lo primero que de seguro viene a la mente del lector es la doctrina del levantamiento del velo societario - que permite que los accionistas respondan por las deudas a cargo de la sociedad - , pero que, para su aplicación, presupone necesariamente la existencia de fraude o abuso de los accionistas en el manejo de la sociedad. Sin embargo, en el caso de Hydrofuerza, ninguno de esos supuestos se presenta; no se desprende en ningún momento que el Estado haya tenido "manejos" que puedan ser considerados como fraude o abuso en dicha empresa estatal.

No obstante lo anterior, existe una segunda opción, poco conocida, es cierto, pero que creemos plenamente aplicable al caso, pues permite que un accionista - sin la necesidad de acreditar un fraude o abuso (pero sí otros requisitos, como que la sociedad no tenga patrimonio con el cual asumir sus obligaciones) - responda de manera solidaria por las deudas a cargo de la sociedad: la doctrina del "alter ego". 
Pero ¿podrá aplicarse para que un Estado responda por las obligaciones de la empresa estatal de la que es accionista? Al respecto, en reciente jurisprudencia arbitral - en el laudo recaído en el arbitraje Bridas vs. Turkmenistán, del 2006- se establecieron varios requisitos para que un Estado responda por las obligaciones contractuales de una empresa estatal (de la que es accionista) que celebró un contrato con un tercero, aun cuando dicho Estado no suscribió el acuerdo.

En el indicado fallo arbitral se establece que no es necesario que todos los requisitos concurran simultáneamente, pero sí es indispensable que se presente un perjuicio apreciable a la empresa privada contratante.

Pues bien, algunos de los requisitos son:

- Que el Estado ejerza control sobre la sociedad.

- Que el Estado tenga gran parte del accionariado de la empresa estatal.

- Que el contrato haya sido celebrado en claro beneficio para el Estado.

- De no responder el Estado, se tendría un laudo meramente "declarativo", ya que la empresa estatal no tiene patrimonio alguno, lo que traería un claro perjuicio a la demandante porque no recibiría el pago de sus pretensiones dinerarias por incumplimientos contractuales.

En el caso analizado se cumplen varios de estos requisitos, porque: i) el Estado ejerce el control total de Hydrofuerza, pues es su único accionista; ii) el contrato fue celebrado para beneficio del Estado; iii) el Estado financia completamente el contrato, lo que indica la falta de recurso de la sociedad estatal; iv) el Estado autorizó la celebración del contrato, como puede verse en el exordio; autorizó su resolución; y v) de no participar el Estado en el proceso arbitral, la empresa estatal no asumiría sus obligaciones, pues no cuenta con el capital para ello, lo que traería como consecuencia un claro perjuicio.

Siendo así, creemos que sí es aplicable la doctrina del "alter ego", ya que se presentan varios requisitos para su configuración; sobre todo, aquel que deviene en indispensable: el perjuicio que podría causarse si se encuentra responsabilidad contractual de Hydrofuerza, empresa a la cual, al no tener capital, no podría cobrarse indemnización, salvo que su accionista (el Estado) fuese quien cumpliera con pagarla. 


\section{c. Sobre el cumplimiento defectuoso o no defectuoso del pago respecto a los hitos 8,9 y 10 del contrato reclamado por Boulder}

Como ya anotamos, existió un inconveniente cuando Hydrofuerza pagó en dólares americanos por los avances de obra, en tres oportunidades (hitos 5, 6 y 7), y posteriormente decidió (en los hitos 8, 9 y 10) pagar en la moneda nacional de Costa Dorada, es decir, en "espadas".

Pero eso no era lo único. Los primeros pagos se hicieron en la cuenta de Boulder en Marmitania (país donde se constituyó), y los siguientes, en la cuenta que esta empresa tenía en Costa Dorada.

Siendo así, eran dos los cuestionamientos de Boulder sobre el pago de los hitos 8, 9 y 10: a) de lugar de pago; y b) de moneda de pago.

En cuanto al lugar de pago, en tanto el contrato no hace ninguna referencia sobre el particular, sostenemos que se aplica de manera supletoria la Ley de Costa Dorada, ya que esta norma fue la que se estableció en aquel.

Pues bien, el artículo 6.1.8 de la Ley de Costa Dorada preceptúa que el pago por transferencias de fondos puede realizarse en cualquier cuenta comunicada por el acreedor. Por otro lado, el artículo 6.1.6 señala que se paga en el domicilio del acreedor en defecto de pacto, que es lo que alegaba Boulder para sostener que el pago debía ser en Marmitania.

¿Qué norma es la aplicable? Pensamos que el artículo 6.1.8, pues regula el supuesto que se viene discutiendo, es decir, el pago por transferencias de fondos. Es evidente, además, que la cuenta de Boulder en Costa Dorada fue comunicada por esta empresa, pues de otra forma la empresa estatal no hubiera podido acceder a ella. Nótese que por el secreto bancario, las cuentas bancarias solo las conocen los bancos y sus clientes, y no se comunican a terceros. Eso es claro.

$\mathrm{Al}$ respecto, debe indicarse que si bien los pagos por los hitos 5, 6 y 7 se hicieron en la cuenta de Marmitania (país de Boulder), no constituye un estoppel o un acto contrario a los "actos propios" el que posteriormente se comience a pagar en la cuenta en Costa Dorada, como argumentaba en este punto Boulder, por una sencilla razón: Hydrofuerza siempre actuó conforme al contrato que, por aplicación supletoria de la Ley de Costa Dorada, permitía el pago en cualquier cuenta comunicada por la acreedora. 
En todo caso, consideramos que los gastos en los que tenía que incurrir Boulder por trasladar el monto depositado, en otra cuenta, a su cuenta en Marmitania, solo les son imputables a dicha empresa, pues si quería que se le pagara exclusivamente en la cuenta de su país, debió preverlo así en el momento de celebrar el contrato.

En segundo lugar, respecto a la moneda de pago, debe indicarse que la cláusula 14.1.2 del contrato es clarísima, pues indica que se puede pagar en "cantidad equivalente" a US\$100 millones de dólares, con lo que coincidimos con la posición de Hydrofuerza, pues se entiende que la común intención de las partes siempre fue que los dólares fueran una moneda solo referencial. En todo caso, no hay ningún perjuicio para Boulder, porque podía acudir a cualquier institución financiera y cambiar la cantidad entregada - al tipo de cambio de venta del día - , a dólares.

Un argumento interesante de Boulder era que cada parte debía soportar los gastos de cumplimiento de su obligación conforme a lo dispuesto por el artículo 6.1.8 de la Ley de Costa Dorada. Entonces, para cumplir su prestación, Hydrofuerza debía encargarse de depositar tal cual lo había realizado anteriormente. Sin embargo, debe precisarse que tal argumento olvida que la prestación de Hydrofuerza queda ejecutada con el depósito financiero (segundo párrafo del 6.1.8 de la misma ley).

Por último, debe indicarse que una circunstancia interesante que hay que evaluar es que, luego de la celebración del contrato, entró en vigencia el Decreto 003, según el cual — desde ese momento y en adelantelas obligaciones a cargo del Estado debían pagarse en moneda nacional.

¿Qué pasaba, entonces, con los contratos ya celebrados? Pues en la norma se dispuso que, de haberse pactado una forma de pago diferente en un contrato previo a su vigencia, dicha forma no cambiaría. Siendo así, la fórmula de "pago equivalente" contenida en el contrato analizado, en tanto fue pactada por las partes y es una forma de pago distinta al pago en moneda nacional, no resulta modificada por el Decreto 003.

\section{d. Respecto a la contratación del tercero para que ejecute la obra en lugar de Hydrofuerza}

Estamos de acuerdo con la posición de Boulder, en el sentido de que la toma, por manifestantes, de la única carretera que tenía acceso al Valle de la Penuria - lugar donde se ejecutaba el proyecto de la central 
hidroeléctrica-, es un evento de fuerza mayor, pues el contrato establece de manera expresa que los "bloqueos" lo son.

Aunque podría decirse que un hecho así no es imprevisible (uno de los requisitos legales para la configuración de un evento de fuerza mayor es su imprevisibilidad, así como que sea irresistible y extraordinario), pues en Costa Dorada los bloqueos eran casi "el pan de cada día", lo cierto es que, como las partes establecieron en forma expresa que los bloqueos eran un evento de fuerza mayor, no puede argumentarse lo contrario, pues ello implicaría ir en contra de la voluntad de los contratantes.

El indicado evento concluyó el 21 de agosto del 2010 (había empezado el 15 del mismo mes). Sin embargo, pese a que Boulder comunicó que había realizado ciertos avances futuros (necesarios conforme al contrato, incluso ante un evento de fuerza mayor), cuando el Ministerio de Obras Públicas, Transportes e Infraestructura (en lo sucesivo, el MOPTI) fue a fiscalizar las obras el 12 de setiembre del 2010, no encontró dichos avances, y lo único que apreció es que la obra estaba avanzada en un $60 \%$, cuando, para ese momento, debía estarlo en un $80 \%$.

En vista de ello, de acuerdo con la cláusula 13.1.2 del contrato, se contrató a un tercero (Fast Solutions S. A.) para que ejecute la obra, pues Boulder no había hecho un "avance sustancial" en dos meses.

Debe señalarse que Hydrofuerza debía solicitar el monto correspondiente a los servicios de Fast Solutions S.A. como reparación - no así como una obligación contractual-, porque luego dicha empresa resolvió el contrato. También cabe indicar que para la contratación de Fast Solutions S. A. no se requería de la convocatoria a una licitación pública, debido a la situación de urgencia (falta de avance de un proyecto de infraestructura de interés público), de acuerdo con la Ley de Contrataciones de Costa Dorada.

Por último, un argumento adicional de Boulder era que la contraprestación por los servicios de Fast Solutions S. A. era muy alta. Al respecto, opinamos que no era así si consideramos que esta última estaba accediendo a continuar con un proyecto ya iniciado y que había generado convulsión social, pues estaba muy politizado. Además, retomar una construcción ya iniciada no permite a la nueva empresa obtener los mismos precios que se logran al comprar grandes cantidades de insumos o al contratar servicios; dicho en otras palabras, la economía de escala es menor por una obra más pequeña (o por una obra a medio construir). 


\section{e. La resolución del contrato fue legítima}

Es lo que sostenemos, pues Boulder no cumplió con su obligación respecto al avance de obra y tampoco con el pago por los servicios del tercero que debió terminar la obra: Fast Solutions S. A.

$\mathrm{Al}$ respecto, cuando nos tocó defender a Boulder indicamos que lo correcto era deducir una excepción de incumplimiento, pues Hydrofuerza se encontraba en situación de incumplimiento y, por ello, no podía solicitar el pago de contraprestación alguna. Sin embargo, el problema de dicha argumentación es que el ejercicio de dicha excepción no fue opuesto a Boulder.

Es discutible si ello era exigible bajo la Ley de Costa Dorada; en realidad, no se decía expresamente en dicha norma. Sin embargo, la doctrina es prácticamente unánime al señalar que se requiere de la comunicación para el ejercicio de la excepción de incumplimiento.

Por otro lado, entendemos que Hydrofuerza utilizó adecuadamente el mecanismo para incumplimientos insubsanables, previsto por la cláusula 26.3 del contrato. Y es que si bien, en un primer momento, el avance en la obra podía ser subsanado, con el paso del tiempo el atraso lo volvió insubsanable. Se volvió insubsanable desde cuando Boulder comunicó que no iba a cumplir hasta que se le paguen diversos hitos (para los que no correspondía el cumplimiento, porque dicha empresa no avanzó el porcentaje previsto para ellos) y que tampoco iba a cumplir con el pago de lo ejecutado por Fast Solutions S. A.

Por último, no hay problema con que no se haya enviado una carta notarial, que es un cuestionamiento realizado por Boulder al mecanismo de resolución contractual, por cuanto la razón de ello era solo dotar a la comunicación de fecha cierta y seguridad. Como nadie cuestiona la fecha ni la entrega, entonces no hay problema alguno y la resolución es válida.

\section{Nuestra experiencia en la Competencia y las recomendaciones}

La experiencia fue invalorable. Si bien no obtuvimos los resultados que hubiéramos esperado, en tanto no estuvimos en las instancias finales de la Competencia, lo cierto es que la experiencia y el know how que nos brindó elaborar - sólo los integrantes del grupo- los escritos de demanda y contestación y, por sobre eso, confrontar nuestras ideas oral- 
mente frente a un tribunal arbitral y contra otros grupos de universitarios, fueron realmente muy importantes para nosotros.

En mi caso particular, aprendí mucho acerca de cómo esquematizar de mejor manera mi exposición, cómo convencer de mejor manera a un tribunal, cómo responder a sus preguntas, cómo estar preparado para sus repentinas interrogantes, cómo refutar rápidamente las ideas planteadas por la otra parte $y$, lo que es más importante, cuál es la mejor manera de hacer esto último.

Algo muy positivo de la Competencia es que, luego de cada audiencia, los árbitros se encargaban de realizar un feedback respecto a la participación de cada uno; dicho de otro modo, de acuerdo con su criterio, nos explicaban: i) qué dijimos bien; ii) cuál era la mejor manera de plantear un determinado argumento; iii) cómo deberíamos haber iniciado y concluido la exposición; etcétera.

Incluso, el solo hecho de estar frente a un tribunal y con la "contraparte" al otro lado era muy importante como entrenamiento para nuestro futuro ejercicio profesional, como también lo era el simple hecho de "perderle el miedo" a expresar las ideas que hemos aprendido en las aulas y que debemos formular ante cualquier autoridad a fin de defender un interés jurídicamente relevante.

Tanto mi grupo como yo recomendamos que los alumnos participen en este tipo de competencias; del valor agregado que les brindan a la preparación que se otorga en las aulas y a las prácticas preprofesionales no puede dudarse. Además, no debe perderse de vista que se está representando a la Universidad de Lima.

Ahora bien, para participar en estas competencias es recomendable que los alumnos procuren buscar ayuda de especialistas en materia de argumentación jurídica. Cuando llegamos a la Competencia pudimos apreciar que el nivel era sumamente alto, pues muchos grupos se habían preparado durante meses (incluso años) en el aspecto oral.

Pero también pudimos comprobar que nuestro nivel académico ( $\mathrm{y}$ esto no es adornarnos) era superior al de muchos de los grupos internacionales. La diferencia es que, más allá de la solidez y el fundamento jurídico de la posición que uno tiene, es fundamental el poder convencer (y esto sólo la experiencia lo proporciona) a un tercero de que aquello que uno viene señalando es lo correcto. 
Entonces, la experiencia que proporciona este tipo de competencia es incuestionablemente importante. De hecho, podría haber más competencias en la universidad; de ese modo, se prepararía a los alumnos a fin de que luego, internacionalmente, puedan destacar aún más.

Nuestro grupo obtuvo un buen puntaje, aunque nos quedamos con la sensación de que si hubiéramos tenido mayor experiencia en este tipo de certámenes, nuestra suerte hubiera sido otra.

Recomiendo que los alumnos participen en este tipo de eventos, pues brindan la posibilidad de desarrollar habilidades que solo así pueden implementarse. Como ya dijimos, en el futuro, los alumnos de hoy y abogados de mañana tendrán que convencer de lo jurídicamente correcto de su posición a varias autoridades. Es más, en el marco de las negociaciones previas a la suscripción de un contrato, los abogados también deben buscar introducir las cláusulas que sean más favorables para su cliente. En eso consiste la tarea del abogado.

Por ello, no deben dejarse pasar oportunidades como esta, pese a que muchos puedan pensar que no cuentan con mucho tiempo libre porque practican en algún estudio jurídico o en el área legal de una empresa o entidad pública. Estamos ante la ocasión de obtener una habilidad imprescindible para nuestro desarrollo profesional y que nos dará un plus o valor agregado por sobre aquellos que no han desarrollado la posibilidad de expresar, confrontar y comunicar sus ideas con convicción y con el animus de convencer a un tercero de lo correcto de una posición. 